\title{
An Efficient Test of Fiscal Sustainability
}

\author{
VASCO J. GABRIEL* \\ University of Surrey, UK and NIPE-UM
}

PATAAREE SANGDUAN

Bureau of the Budget, Thailand

\begin{abstract}
We suggest using the efficient test with pre-specified cointegration vectors of Horvath and Watson (1995) for the 'strong' fiscal sustainability hypothesis. Unlike this procedure, conventional methodologies tend to penalize the sustainability hypothesis.
\end{abstract}

JEL Classification: C32; E62; H60

\section{Introduction}

Testing the sustainability of a given country's fiscal stance has attracted a great deal of attention. There is, however, a contradiction between the predictions of empirical models, which point to a significant degree of unsustainability across different countries, and the relative scarcity of episodes of full-scale defaults. Therefore, it is of great importance to reassess empirical methodologies dealing with the analysis of fiscal sustainability. We show that once an appropriate testing method is put to use, the paradoxical findings of earlier literature virtually disappear.

Tests of fiscal sustainability are commonly based on the government's intertemporal budget constraint (IBC) in its present value form (see Haug, 1991, Hakkio and Rush, 1991, Ahmed and Rogers, 1995). Given that government expenditures (inclusive of interest payments) $G G_{t}$ and revenues $R_{t}$ usually display non-stationary behaviour, this provides a statistical framework for testing sustainability, as this implies that these variables must be cointegrated. In practice, the equation

$$
R_{t}=a+b G G_{t}+u_{t}
$$

is estimated and, depending on the cointegration vector $[1,-b]$ obtained, we may have:

- 'Strong' sustainability, if $R_{t}$ and $G G_{t}$ are cointegrated and $b=1$;

${ }^{*}$ Corresponding author. Address: Department of Economics, University of Surrey, Guildford, Surrey, GU2 7XH, UK. Email: v.gabriel@surrey.ac.uk. Tel: + 441483 682769. Fax: + 441483689548. 
- 'Weak' sustainability when $R_{t}$ and $G G_{t}$ are cointegrated, but $0<b<1$ : a smaller than 1 long-run elasticity of revenue relative to expenditure may signal debt default;

- Unsustainability, when $b \leq 0$, implying that deficits are being accumulated at a rate greater than the growth rate in the economy and the IBC is therefore violated.

Cointegration inference usually involves two stages: i) testing for cointegration, assuming the cointegration vector is unknown; ii) if cointegration is found, proceed with estimation, with cointegration maintained both under the null and the alternative, with a 'restricted' cointegration vector arising from the first step. An alternative, stricter test of the 'strong' sustainability hypothesis implied by the IBC may be obtained by testing the stationarity of the primary surplus $P S_{t}=R_{t}-G G_{t}$.

Horvath and Watson (1995), however, point out that standard tests are inefficient in this situation. These authors derived a multivariate testing procedure for the case when the cointegration vector is known, which allows for substantial gains in power relative to standard procedures. Thus, we depart from, and thus contribute to, the literature by using the Horvath-Watson efficient test of the 'strong' sustainability hypothesis, when the cointegration vector is pre-specified as $[1,-1]$. This approach can also lead to efficiency gains over univariate tests if shocks to $G G_{t}$ and $R_{t}$ are correlated, which is likely to be the case. A potential caveat of this test is that its relative power may suffer if the variables are cointegrated with a cointegrating vector different form the pre-specified one, namely the case of 'weak' sustainability. We argue, however, that given the implications of the latter, the 'strong' hypothesis should be the benchmark case when assessing fiscal sustainability.

\section{Testing for cointegration with pre-specified cointegration vec- tors}

The setup for the derivation of the test is similar to the reduced rank procedure based on a Gaussian Vector error-correcting model (VECM)

$$
\Delta X_{t}=\Pi X_{t-1}+\sum_{i=1}^{p-1} \Phi_{i} \Delta X_{t-i}+\varepsilon_{t}
$$


where $Y_{t}$ and $X_{t}$ are $n \times 1$ variables and $\varepsilon_{t}$ is normally distributed with covariance matrix $\Sigma_{\varepsilon}$. A test for $r=\operatorname{rank}(\Pi)$ can be developed for the hypotheses

$$
\begin{aligned}
& H_{o}: \operatorname{rank}(\Pi)=r=r_{o} \\
& H_{a}: \operatorname{rank}(\Pi)=r=r_{o}+r_{a}, \quad r_{a}>0 .
\end{aligned}
$$

The alternative hypothesis contains $r_{a}$, the number of additional cointegrating vectors present under $H_{a}$. We can partition the ranks according to the number of (un)known cointegration vectors, that is, $r_{o}=r_{o_{k}}+r_{o_{u}}$ and $r_{a}=r_{a_{k}}+r_{a_{u}}$, the subscripts $k$ and $u$ indicating 'known' and 'unknown', respectively.

To derive the test statistic, we factor $\Pi$ as $\Pi=\delta \alpha^{\prime}$, so that $\delta$ and $\alpha$ are $n \times r$ matrices of full column rank and the columns of $\alpha$ give the cointegration vectors. These matrices are partitioned into $\alpha=\left(\alpha_{o} \alpha_{a}\right)$ and $\delta=\left(\delta_{o} \delta_{a}\right)$ and, to reflect the knowledge of the cointegration vector, $\alpha_{a}=\left(\alpha_{a_{k}} a_{a_{u}}\right)$ and $\delta_{a}=\left(\delta_{a_{k}} \delta_{a_{u}}\right)$, so that the $r_{a_{k}}$ columns of $\alpha_{a_{k}}$ are the additional known cointegration vectors under $H_{a}$. This implies that $\Pi X_{t-1}=\delta_{o}\left(\alpha_{o}^{\prime} X_{t-1}\right)+\delta_{a}\left(\alpha_{a}^{\prime} X_{t-1}\right)$.

In our analysis, we test $H_{o} \mathrm{\vee} H_{a}$ such that $r_{o}=0$ (i.e., no cointegration) and $r_{a}=r_{a_{k}}=1$, since we have a single, pre-specified cointegration vector $[1,-1]$ implied by IBC. The model can be rewritten as

$$
\Delta Y_{t}=\delta_{a_{k}}\left(a_{a_{k}}^{\prime} Y_{t-1}\right)+\beta Z_{t}+\varepsilon_{t}
$$

where $\beta=\left(\Phi_{1} \Phi_{2} \ldots \Phi_{p-1}\right)$ and $Z_{t}=\left(\Delta Y_{t-1}^{\prime} \Delta Y_{t-2}^{\prime} \ldots \Delta Y_{t-p+1}^{\prime}\right)$. Let $Y=\left[Y_{1} Y_{2} \ldots Y_{T}\right]^{\prime}, \Delta Y=$ $Y-Y_{-1}, Z=\left[Z_{1} \ldots Z_{T}\right], \varepsilon=\left[\varepsilon_{1} \ldots \varepsilon_{T}\right]$ and $M_{Z}=\left[I-Z\left(Z^{\prime} Z\right)^{-1} Z^{\prime}\right]$. The Wald statistic for $H_{o}$ against $H_{a}$ is

$$
W=\left[\operatorname{vec}\left(\Delta Y^{\prime} M_{z} Y_{-1} \alpha_{a_{k}}\right)\right]^{\prime}\left[\left(\alpha_{a_{k}}^{\prime} Y_{-1}^{\prime} M_{z} Y_{-1} \alpha_{a_{k}}\right)^{-1} \otimes \hat{\Sigma}_{\varepsilon}^{-1}\right]\left[\operatorname{vec}\left(\Delta Y^{\prime} M_{z} Y_{-1} \alpha_{a_{k}}\right)\right]
$$

where $\hat{\Sigma}_{\varepsilon}^{-1}$ is the OLS (MLE, given the Gaussianity assumption) estimator of $\Sigma\left(\hat{\Sigma}_{\varepsilon}=T^{-1} \hat{\varepsilon}^{\prime} \hat{\varepsilon}\right)$ and $\left(\Delta Y^{\prime} M_{z} Y_{-1} \alpha_{a_{k}}\right)\left(\alpha_{a_{k}}^{\prime} Y_{-1}^{\prime} M_{z} Y_{-1} \alpha_{a_{k}}\right)^{-1}$ is the OLS estimator of $\delta_{a_{k}}$.

Horvath and Watson (1995) show that (3) has an asymptotic distribution that depends on Wiener processes. Our empirical application corresponds to Case 2 when $n-r_{o_{u}}=2$, $r_{o_{k}}=r_{a_{u}}=0, r_{a_{k}}=1$. We allow for a constant term in the VECM, as the variables may contain trends. Critical values are 13.73. 10.18 and 8.30, for the $1 \%, 5 \%$ and $10 \%$ significance levels, respectively (see Table 1 of Horvath and Watson, 1995, pp. 996-998). 


\section{$3 \quad$ Empirical analysis}

For illustration purposes, we test the fiscal sustainability of the Bahamas, Finland, France, South Africa, Thailand and the United States, using quarterly data spanning from 1975 to 2005, collected from the IFS database. While initial studies have focused on developed economies (see Payne, 1997), increasing attention has been devoted to the fiscal stance of developing countries (see Kalyoncu, 2005). Empirical evidence is ambiguous, suggesting that 'weak' sustainability is pervasive, particularly for developing economies. This section revisits this evidence, first using standard tests, then applying the Horvath-Watson procedure.

We implement the univariate approach for testing 'strong' sustainability by using the ADF, Phillips-Perron (PP) and Elliot-Rothenberg-Stock (ERS) unit root tests on $P S_{t}$ (with a constant term included, lag lengths and bandwidths of the Bartlett kernel automatically selected based on the SIC). Results in Table 1 show that for the Bahamas and France, $P S_{t}$ displays stationary and, hence, sustainable behaviour. The picture is less clear for the USA, given that the PP test does not reject the null of a unit root, whereas Finland, South Africa and Thailand appear to be on an unsustainable path.

A multivariate approach using the joint dynamics of expenditures and revenues, and relaxing the assumption of a cointegration vector of $[1,-1]$, is arguably more efficient. Hence, we estimate (1) using OLS estimation and the Dynamic OLS efficient estimator ${ }^{1}$ of Stock and Watson (1993), testing whether $b=1$ or $0<b<1$. We ascertain whether the estimated equilibrium errors are stationary or not by means of cointegration counterparts of the ADF and PP tests (AEG and PO). There are no efficiency losses in pursuing this route when compared to the multi-equation method of Johansen (1988), as we are studying a bivariate relationship with potentially a single cointegration vector.

We observe from Table 2 that, in general, the OLS estimates tend to be further away from 1 than the corresponding DOLS estimates $\left(\hat{b}_{D O L S}\right)$. This would imply that the Bahamas, Finland and France would be classified as 'weakly' sustainable, whilst the remaining countries would be considered 'strongly' sustainable. Examining the DOLS results, however, all countries display estimates close to the 'strong' sustainability benchmark, with the exception of Finland.

Note that this analysis is conditional on the existence of cointegration between expenditures and revenues. Looking at the AEG test with OLS residuals, one would conclude that Thailand, Finland and the USA fail to meet the sustainability criteria. Interestingly, however, the

\footnotetext{
${ }^{1}$ We determine the number of extra leads and lags $p$ by testing down their significance, starting from $p=4$.
} 
Phillips-Ouliaris test indicates that only the US would not be sustainable. Considering the tests with DOLS residuals, the AEG points to unsustainability for all countries with the exception of France. The PO test, on the other hand, adds South Africa and the Bahamas to the latter. Therefore, a contradiction seems to emerge: by employing a theoretically more appealing estimator, it appears that the case for sustainability is weakened, although the point estimates suggest that the cointegration vector is indeed $[1,-1]$.

To disentangle this issue, we employ the efficient Wald statistic (3), estimating (2) (lag length established with the SIC criterion) and testing the rank of matrix $\Pi$. The results of the test are displayed in the rightmost column of Table 2 (under H-W Wald test). It is interesting to notice that the null hypothesis of no cointegration is rejected quite comfortably, at the $1 \%$ significance level, for all countries. This suggests that these countries pursue a strongly sustainable fiscal policy. It appears that the results of conventional methodologies tend to penalize the sustainability hypothesis, even when the estimated $b$ is close to 1 . This could be explained by the fact that the inefficiency of conventional tests may lead to loss of power of unit root and cointegration tests and, therefore, that the null hypothesis of no cointegration is rejected less often than it should.

\section{Conclusion}

We revisited the empirical evidence on fiscal sustainability analysis using Horvath and Watson's (1995) efficient cointegration test. This framework accounts for the likely correlation between innovations to revenues and expenditures and it incorporates the appropriate theoretical restriction on the cointegration vector. When this procedure is employed, the empirical support for the 'strong' sustainability hypothesis is quite convincing, with the null of no cointegration being comfortably rejected for all countries.

\section{References}

[1] Ahmed, S. and Rogers, J. (1995), Government budget deficits and trade deficits Are present value constraints satisfied in long-term data?, Journal of Monetary Economics, 36, 351-374.

[2] Hakkio, C. and Rush, M. (1991), Cointegration and Government Borrowing Constraints: Evidence for the United States, Journal of Business and Economic Statistics, 9, 429-445. 
[3] Haug, A. (1991), Cointegration and Government Borrowing Constraints: Evidence for the United States, Journal of Business and Economic Statistics, 9, 97-101.

[4] Horvath, M. and Watson, M. (1995), Testing For Cointegration When Some of the Cointegrating vectors are Prespecified, Econometric Theory, 11, 984-1014.

[5] Johansen, S. (1988), Statistical Analysis of Cointegration Vectors, Journal of Economic Dynamics and Control, 12, 231-254.

[6] Kalyoncu, H. (2005), Fiscal policy sustainability: test of intertemporal borrowing constraints, Applied Economics Letters, 12, 957-962.

[7] Payne, J. (1997), International evidence on the sustainability of budget deficits, Applied Economics Letters, 4, 775-779.

[8] Stock, J. and Watson, M. (1993), A Simple Estimator of Cointegrating Vectors in Higher Order Integrated Systems, Econometrica, 61, 783-820. 
Table 1: Unit root tests for the Primary Surplus series

\begin{tabular}{lllllll}
\hline \hline & \multicolumn{3}{c}{ Levels } & \multicolumn{3}{c}{ First-difference } \\
& ADF & PP & ERS & ADF & PP & ERS \\
Bahamas & $-4.381^{* *}$ & $-4.454^{* *}$ & $1.001^{* *}$ & $-10.608^{* *}$ & $-15.013^{* *}$ & $0.226^{* *}$ \\
Finland & -1.859 & -2.358 & -3.657 & $-11.242^{* *}$ & $-16.210^{* *}$ & $0.259^{* *}$ \\
France & $-7.846^{* *}$ & $-8.350^{* *}$ & $0.465^{* *}$ & $-9.251^{* *}$ & $-14.647^{* *}$ & $0.946^{* *}$ \\
South Africa & -1.133 & -1.467 & 20.411 & $-5.514^{* *}$ & $-10.104^{* *}$ & $2.489^{*}$ \\
Thailand & -1.713 & -3.371 & 4.476 & $-12.044^{* *}$ & $-16.147^{* *}$ & $0.267^{* *}$ \\
United States & $-3.022^{*}$ & -0.842 & $0.021^{* *}$ & -2.502 & $-15.505^{* *}$ & 6.654 \\
\hline
\end{tabular}

Note: ${ }^{*}$ significant at $5 \%,{ }^{* *}$ significant at $1 \%$

Table 2: Cointegration analysis

\begin{tabular}{|c|c|c|c|c|c|c|c|}
\hline & $A E G$ & $P O$ & $\hat{b}$ & $A E G_{D O L S}$ & $P O_{O L S}$ & $\hat{b}_{O L S}$ & HW-Wald test \\
\hline Bahamas & $-3.460^{*}$ & $-12.575^{* *}$ & $\begin{array}{l}0.899 \\
(0.042)\end{array}$ & -3.324 & $-9.395^{* *}$ & $\begin{array}{l}0.972 \\
(0.036)\end{array}$ & $30.516^{* *}$ \\
\hline Finland & -2.015 & $-3.555^{*}$ & $\begin{array}{l}0.813 \\
(0.042)\end{array}$ & -1.609 & $-2.866^{* *}$ & $\begin{array}{l}0.824 \\
(0.046)\end{array}$ & $15.553^{* *}$ \\
\hline France & $-7.671^{* *}$ & $-8.229^{* *}$ & $\begin{array}{l}0.825 \\
(0.067)\end{array}$ & $-4.353^{* *}$ & $-6.956^{* *}$ & $\begin{array}{l}1.013 \\
(0.059)\end{array}$ & $29.181^{* *}$ \\
\hline South Africa & $-3.670^{*}$ & $-7.049^{* *}$ & $\begin{array}{l}0.929 \\
(0.035)\end{array}$ & -2.836 & $-3.761^{*}$ & $\begin{array}{l}0.975 \\
(0.031)\end{array}$ & $14.270^{* *}$ \\
\hline Thailand & -1.725 & $-3.378^{*}$ & $\begin{array}{l}1.005 \\
(0.034)\end{array}$ & -1.672 & -2.519 & $\begin{array}{l}1.008 \\
(0.033)\end{array}$ & $14.602^{* *}$ \\
\hline United States & -2.469 & $-2.736^{* *}$ & $\begin{array}{l}0.969 \\
(0.026) \\
\end{array}$ & -2.499 & -2.196 & $\begin{array}{l}0.978 \\
(0.026)\end{array}$ & $46.194^{* *}$ \\
\hline
\end{tabular}

Note: see Table 1; standard errors in brackets 